\title{
Sufismo e taoísmo: do xamanismo à formulação filosófica
}

Sufism and Taoism: from Shamanism to philosophical formulation

\author{
Cecilia Cintra Cavaleiro de Macedo ${ }^{\mathrm{I}}$
}

\begin{abstract}
Resumo: Em sua obra Sufismo e Taoísmo, Toshihiko Izutsu aponta o paralelismo existente entre estas duas correntes aparentemente díspares. Um ponto fulcral no qual se apoia o estudo comparativo de Izutsu é a origem xamânica dos dois movimentos sapienciais. Tomando como correta esta raiz apontada por Izutsu, pretendemos discutir neste artigo como estas "experiências xamânicas" podem ter dado origem a filosofias tão sofisticadas e elaboradas. Isso será realizado através do questionamento da localização destes dois fenômenos entre a filosofia e a religião, passando pela discussão do significado do termo Sufismo e seguindo em direção à caracterização destes como expressões de experiências que só podem ser entendidas no âmbito da mística que, sob alguns aspectos, é diferente tanto da religião quanto da filosofia.
\end{abstract}

Palavras-chave: Sufismo; Taoísmo; Izutsu; Mística; Xamanismo.

Abstract: In his work Sufism and Taoism, Toshihiko Izutsu drew a parallel between these two apparently disparate schools of thought. One of the crucial factors that supports Izutsu's comparative study is the shamanic origin of both paths of wisdom. Assuming this origin as correct, we intend to discuss in this paper how these "shamanic experiences" could have originated such elaborate and sophisticated philosophies. This will be achieved through questioning the place of both phenomena in face of religion and philosophy, discussing the meaning of Sufism and proceeding to their characterization as experiences that can only be understood in the scope of mysticism, that, in some aspects, differs from religion and philosophy.

Keywords: Sufism; Taoism; Izutsu; Mysticism; Shamanism.

I Doutora em Ciências da Religião pela Pontifícia Universidade Católica de São Paulo. Professora na Universidade Federal de São Paulo. ceciliacmcavaleiro@gmail.com. orcid.org/oooo-ooo2-8321-6944 


\section{Os problemas do estudo do Sufismo e do Taoísmo nos moldes tradicionais da filosofia e da religião}

Em sua obra Sufismo e Taoísmo, Toshihiko Izutsu chama a atenção para o paralelismo existente entre estas duas correntes aparentemente díspares, dedicando-se a indicar pontos que podem ser entendidos como comuns. Da parte do taoísmo, este autor, que foi por boa parte de sua vida radicado no Irã, concentra sua análise no Dao De Jing, atribuído ao lendário Lăozi, e em Zhuāngzǐ; e como representante do Sufismo, analisa a obra de Ibn 'Arabi. Izutsu apresenta um extenso levantamento e discussão das noções fundamentais, princípios básicos e categorias essenciais, tanto do Taoísmo, quanto do Sufismo, dividido em dois volumes, cada um deles concentrado em uma das duas tradições.

$\mathrm{O}$ esforço de Izutsu foi baseado em sua crença de que uma série de elementos presentes em determinada comunidade e que são considerados como constitutivos ou próprios desta, poderiam ser identificados sob formas diferentes, mesmo se apresentados em linguagem diferente, também em outras tradições sem qualquer parentesco histórico ou proximidade geográfica que pudesse indicar uma influência. Com sua crença, ele acreditava ser possível estimular a harmonia entre os povos. Particularmente, concordo com Izutsu e creio que a maioria das ideias básicas de uma tradição pode ser encontrada no seio de cada uma das grandes tradições da humanidade, ainda que formulada em outra linguagem, adaptada a cada cultura e meio social, ou, ainda, pode estar presente em vertentes minoritárias, marginalizadas ou alijadas do mainstream cultural ou religioso. Isso se deve ao fato de que a estrutura fundamental do espírito humano - seja o termo espírito entendido enquanto o funcionamento do cérebro ou enquanto um conjunto de pensamentos mais sutis - é a mesma e isso provoca um repertório comum de experiências e percepções, as quais são formuladas de modo diferente em cada uma das culturas e tradições nas quais se manifesta, para fins de representação e comunicação.

\section{Taoísmo: entre a religião e a filosofia}

Um primeiro ponto interessante a refletir é justamente a relação um tanto conturbada de ambas as tradições abordadas por Izutsu, tanto com a categoria de religião, quanto com a de filosofia. Se, por um lado, a tradição ocidental de matriz grega poderia questionar a aplicação do qualificativo filosofia às grandes obras do pensamento chinês, o qualificativo religião também não lhe parece servir ser muito adequado ${ }^{1}$. Sem um Deus pessoal ou uma estrutura fixa de crenças que se baseiam numa realidade transcendente ao mundo sensível, o chamado taoísmo religioso (Daojiao) veio a se desenvolver a posteriori, ritualizando um material que originariamente foi fruto do mais alto pensamento especulativo. Nesse sentido, disseminou-se a ideia de que haveria dois tipos de expressão distintos, um que se referia a um tipo de discussão mais filosófica (Jia) consistindo no ensinamento Taoísta em si (Daojia) e outro referente às práticas e rituais de cunho mais religioso (Jiao). Muitos estudiosos apontam a formulação filosófica como anterior, tendo

\footnotetext{
${ }^{1}$ Esta tarea podría empezar a realizarse con el reconocimiento de que el propio concepto de "religión” no existe en la lengua clásica china. Que “zongjiao” es un neologismo, como tantos, introducido desde el japonés en el acervo léxico chino a partir del siglo XX, y que su campo semántico se amplió del cristianismo inicial a todo el resto de religiones mundiales, alcanzando con posterioridad, también a las de origen chino: confucianismo y daoísmo. Lectura de la relación religiosa y filosófica del daoísmo chino. TEROL ROJO, Lectura de la relación religiosa y filosófica del daoísmo chino, p. 234.
} 
sido a entrada e disseminação do Budismo na China um dos elementos que conduziu o Taoísmo a adotar uma expressão mais religiosa².

Mais recentemente, essa divisão vem sendo questionada, principalmente se nos ativermos ao fato de que estes termos - religião e filosofia - do modo como os utilizamos no "ocidente" inexistem nos próprios textos e mesmo na antiga língua chinesa. Consequentemente, esta divisão seria arbitrária e exógena. "Os sucessivos Daozang [Cânones Daoistas] jamais fizeram esta distinção. Quando olhamos para o modo em que os termos Daojia e Daojiao ocorrem nos textos preservados no Cânone Ming [publicado em 1445], vemos que eles são praticamente sinônimos e intercambiáveis3". Infelizmente, ao estudarmos sob uma perspectiva comparativa os pensamentos de diferentes tradições, é forçoso que nos deparemos com problemas como este, quanto a se e a o que podemos realmente classificar no âmbito da filosofia ou da religião, já que estes termos foram moldados e definidos historicamente pela tradição ocidental cristã, muitas vezes, não tendo sequer paralelos em tradições que não compartilham dos mesmos princípios básicos.

\section{Sobre a definição de Sufismo e a mística islâmica}

Quanto ao Sufismo, outro termo delicado, deveremos, num primeiro momento, também abrir uma licença, posto que somos praticamente obrigados a entender o termo tal como ficou conhecido modernamente, ou seja, na sua acepção mais ampla, quase como um sinônimo de mística islâmica. Há que ressaltar que essa concepção generalista de sufismo é devida, em parte à tentativa de algumas correntes místicas de se sobreporem às demais, em parte aos historiadores muçulmanos a partir do século XIV. Mas, além disso, deve-se em grande parte, ao olhar ocidental, já que historicamente a mística islâmica teve diversas expressões e formulações e há notáveis diferenças entre a espiritualidade dos diferentes ramos do Islã que a maioria dos estudiosos ocidentais não se deu ao trabalho de valorizar.

O que costumamos chamar de Sufismo nos dias atuais consiste em um grupo de pessoas que se estrutura como uma confraria mística ou ordem, semelhante às ordens monásticas encontradas no cristianismo, cujo suposto fundador seria uma espécie de santo ou personalidade mística excepcional, e que exibe uma linhagem espiritual que remete ao Profeta Mohammad, sua família ou seus companheiros. Vale ressaltar que estas características não se aplicavam, nem de longe, às confrarias místicas que despontaram no

\footnotetext{
${ }^{2}$ The emergence of "Chinese religion" in the post-classical age occurred in the context of China's encounter with Indian civilization. Viewed from China, the indigenous religion proved remarkably receptive to the imprint of Buddhism, introduced via the commercial routes linking China with Central Asia and India, notwithstanding the deep roots of Daoism in the thought system and practices of Chinese antiquity and the fact that the Buddhist ideal of a celibate samgha was fundamentally at odds with the Confucian kinship system and ancestor cult. Indeed, the foreign religion met with near universal success in China - especially in regard to its vision of life after death, its teaching on morality, its practice of iconic representation, mortuary ritual, even monastic life and institutions. That attraction has lasted - or been reborn - despite periodic polemics and incidents of persecution, throughout the formative period of Chinese religion and into the present. It is probably no coincidence that two of the most formative periods in the history of Daoism were also periods of strong interaction with Buddhism: the constitution in the fifth century of the Lingbao scriptural corpus, marking the massive entry of Buddhist doctrines and rituals into the Daoist canon, and the arrival of Tantric forms of Buddhism especially during the Tang dynasty (618-907) that transformed Daoist liturgy, art, and practices under the Song (960-1279). TEISER, VERELLEN. Buddhism, Daoism, and Chinese Religion, p. 1.

3 "The successive Daozang [Daoist Canons] never made this distinction. When we look at the way the terms Daojia and Daojiao occur in the texts preserved in the Ming Canon [published in 1445], we see that they are practically synonymous and interchangeable". SCHIPPER, The Taoist Canon: A Historical Companion to the Daozang, 2004, p. 6.
} 
início do Islã. Efetivamente, este modelo só passou a ser mais frequente a partir do final do século XIII. Os ditos "fundadores" das ordens foram, na maior parte, professores que, não raramente, sequer chegaram a saber que fundaram alguma ordem nestes moldes. Eram homens de reconhecida sabedoria e notável desenvolvimento espiritual que, em sua maioria, morreram sem designar sucessores, como por exemplo, para falar dos maiores e mais famosos, Rumi e o próprio Ibn Arabi. Portanto, para entendermos algo dos primórdios da mística islâmica há que considerar as diferentes vertentes e as notícias e indicações que temos destes próprios mestres e de historiadores cronologicamente mais próximos, independente das ordens que vieram a se estruturar em torno da celebridade de seus nomes após suas mortes.

Em relação ao termo sufismo, podemos dizer que sua origem também é controversa. O nome que foi aplicado à mística islâmica foi tasawwuf. O praticante é o mutasawwifah, e, dentre eles, aquele que chegou a atingir seu objetivo final, ou aos graus mais altos, o sûfi. A origem etimológica da palavra é bastante discutida, não parecendo ter precedentes no idioma árabe. As diferentes explicações são elencadas por Qushairi e vão desde as hipóteses que sustentam que o termo pode ter sido derivado do próprio idioma árabe, a partir de sufah, (uma alusão aos companheiros do Profeta), de safâ (pureza, sinceridade, como uma das características do praticante) ou de sûf (lã, em relação ao manto utilizado pelos andarilhos), até a alternativa proposta por Biruni que advoga ser uma adaptação de uma palavra estrangeira, criada a partir do termo grego sophia ${ }^{4}$. É mais amplamente aceita, por ser historicamente plausível e etimologicamente adequada a derivação a partir do termo sûf (lã).

Junayd explica o termo como procedente da palavra sûf, não por associação do significado direto do termo, mas de outro modo, como um acrônimo a partir da combinação das letras que a compõem. Os significados seriam dados por outras palavras que começam por estas três letras. Suf "se compõe de três letras, sad, waw e fá [ص, و, ف]. Sad é a inicial de sabr (paciência), sedq (sinceridade) e safa (pureza); waw é de wudd (concórdia), wird (litania) e wafa (fidelidade); e com fá começam fard (desapego), faqr (pobreza) e fana (aniquilação)5”. Concretamente, sabemos que, ainda no século II da Hégira (séc. VIII da Era comum) a denominação Sufi designava um certo grupo de ascetas de Kufa (Iraque), provavelmente porque se caracterizavam por usar um manto de lã (sûf) como sinal de penitência.

Quanto às diferenciações entre os diversos grupos místicos dos quais se tinham notícia nos primeiros séculos do Islam, a primeira separação que há de ser feita é em relação à gnose xiita. A espiritualidade xiita é caracterizada por uma perspectiva bem menos ascético-devocional-extática que a maioria das linhas Sufis e mais pela busca de um conhecimento de cunho intelectual, ou, mais propriamente, gnóstico - denominado irfan. Para boa parte do que é denominado Sufismo em geral - e considere-se que a perda de significado do termo e sua utilização indiscriminada são agravadas pelo surgimento de novas ordens africanas e asiáticas, as quais, como o próprio islamismo que se instaurou nestes lugares conquistados a posteriori, assumiram diferentes feições culturais preexistentes - o conhecimento de Deus se dá "através do desvelamento e da visão interior e não pelo intelecto e raciocínio, através do êxtase e estado espiritual e não por especulações e explicações verbais ${ }^{6 "}$. Claro é que, em muitos aspectos, tasawwuf e "irfan se sobrepõem e se

\footnotetext{
${ }^{4}$ QUSHAIRI, Risala, p. 468, apud NURBAKHSH, Simbolismo Sufi, p. 333.

5 JUNAYD, apud NURBAKHSH, Simbolismo Sufi, p. 335.

${ }^{6}$ NURBAKHSH, Simbolismo Sufi, p. 284.
} 
relacionam, uma vez que o objetivo é o conhecimento direto de Deus. Mas há aspectos teóricos e práticos que os diferenciam.

Além desta diferenciação, muito expressiva no período medieval, embora pouco estudada ainda foi também a ação dos círculos Ismailis, e seus missionários ( $d \bar{a} \imath$, pl. du'āt), conhecidos genericamente como batinis. Embora a corrente Ismaili tenha sido muito forte politicamente durante certo período, tendo constituído, inclusive um califado próprio com sede no Cairo, após a queda do califado Fatímida, esta corrente passou a ser perseguida e, até os dias atuais, são vistos como hereges ou não muçulmanos por boa parte das correntes islâmicas. Em virtude da perseguição, desenvolveram diversas formas de sobrevivência e, dentre elas, alguns missionários chegaram a disfarçar-se como Sufis e misturar-se a estes7. Ainda conforme Daftary, isto gerou uma troca real de experiências, ensinamentos, terminologia e metodologia e houve a adoção do ta'wil batini (exegese esotérica) por parte de algumas ordens Sufis, o que conduziu a uma confusão maior entre as abordagens, originariamente, distintas. Duas outras expressões místicas que constituíram movimentos notavelmente diferentes do Sufismo, são Malâmatiyya e Qalandariyya. Estas correntes foram erroneamente confundidas entre si, pois, sob muitos aspectos, eram opostos. Para alguns, os Sufis eram considerados superiores aos demais, para outros, ao contrário:

Diferença entre Qalandar, Malâmati e Sufi: o Qalandar é aquele que está totalmente desprendido tanto do mundo quanto do eu e que se esforça por eliminar todos os costumes; o Malâmati é aquele que se esforça por ocultar seus atos devocionais e o Sufi é aquele cujo coração está totalmente distanciado da criação, de modo que seu nível é mais elevado que o dos outros dois 8 .

Infelizmente, poucas são as notícias que temos do movimento Malâmati, nome dado ao participante da confraria que pode ser entendida como "povo da reprovação" ou o "caminho da culpa". As primeiras notícias que temos de sua presença no mundo islâmico são por volta do século IX E. C. (III da Hégira) e, ao menos em seus primórdios, parece ter sido um círculo constituído primariamente por pessoas da região de Nîshâpûr (Khorasan), sendo, portanto, um movimento notoriamente mais oriental ${ }^{9}$ do que aquele denominado Sufi. Este círculo de pessoas possuía uma rígida regra de vida, que acredita-se ter sido desenvolvida entre os séculos IX e X, mantinham-se voluntaria e intencionalmente nas sombras e no anonimato ${ }^{10}$.

\footnotetext{
7 "During the earliest post-Alamut centuries, the Persian Nizaris increasingly disguised themselves under the mantle of Sufism, without establishing formal affiliations with any one of the Sufi orders or tariqas which were then spreading in Persia. The origins and early development of this curious phenomenon, as noted, remain very obscure. However, modern studies of the meagre literary works of the Nizaris of Persia and Central Asia dating to the early post-Alamut period have clearly revealed that Nizari Isma'ilism did become increasingly infused in pre-Safavid Persia with Sufi teachings and terminology. At the same time, the Sufis themselves used the Isma'ili-related batini ta'wil methodology, or esoteric exegesis, also adopting certain ideas which had been more widely ascribed to the Isma'ilis". DAFTARY, Ismailis in Medieval Muslim Societies, p. 186.
}

${ }^{8}$ Mohammed 'Ala ibn Tahanawi. Kashaf Estelahat al-funum, 156o. apud NURBAKHSH, Simbolismo Sufi, p. 353.

9 Nishapur é a capital da província de Khorasan, hoje uma grande província situada ao leste do Irã. O território de Khorasan, historicamente, estendia-se em direção ao oriente, abrangendo uma região muito maior. Hoje, este território encontra-se dividido entre diversos países além do Irã, como Afeganistão, Turcomenistão, noroeste do Paquistão, Uzbequistão e Tadjiquistão.

${ }^{10}$ As poucas informações historicamente seguras acerca destes misteriosos personagens chegaram até nós através da obra do historiador da mística Sheikh Abû 'Abd al-Rahmân al-Sulamî de Nîshâpûr (937-1021), aparentemente ele próprio um mestre espiritual com conexões íntimas com esta linha. Em sua obra, Epístola dos Malamati (Risâlat al-Malâmatiyya) Sulamî ressalta que estes homens não escreveram nenhum tratado 
Uma das principais características destes místicos é que eles se apresentam, falam e agem como homens comuns, adaptados à sociedade à qual pertencem. Nada de mantos, amuletos distintivos, frases de efeito, linguajar próprio, mendicância ou nomadismo. Os Malâmati se vestiam de modo comum, comportavam-se publicamente como cidadãos medianos, trabalhavam em ofícios como os demais homens, não ostentando qualquer característica que os distinguisse do restante da população. Isso não só era uma característica, como fazia parte da regra de vida. A questão profissional é um ponto importante a ser destacado, sendo que muitos mestres e discípulos pertenceram a guildas e assumiram nomes que sugerem suas respectivas profissões ${ }^{11}$. Isso indica que provavelmente muitos deles ensinavam os conteúdos dessa via mística através dos ensinamentos adaptados dos ofícios que praticavam e que, talvez seus aprendizes fossem, na verdade, discípulos do caminho espiritual ${ }^{12}$.

Por vezes, radicalizavam a regra do anonimato e do misturar-se na multidão, assumindo posições públicas críticas, questionadoras e consideradas reprováveis pela sociedade da época e essa é a razão de ser chamada a Via da Reprovação. Não faziam questão de serem vistos como homens santos ou cidadãos de moral ilibada, ao contrário, atraiam para si, muitas vezes intencionalmente, a má-fama e dúvidas acerca de seu caráter. Longe de terem sido considerados por todos como homens de elevado nível espiritual, muitas vezes foram acusados de hipocrisia, e o desprezo que mantinham em relação às instituições e à própria aparência de "moralismo" e "santidade" foi muitas vezes julgada negativamente por esconder uma secreta valorização, ainda que às avessas, das opiniões alheias.

Em muitos pontos, sua regra de vida se opunha ao discipulado dos demais círculos místicos, posto que sustentavam uma postura bem distante do ascetismo, especialmente dos Sufis. Este ascetismo foi, não poucas vezes, objeto de crítica e desprezo por parte dos Malamati. Certas opiniões que defendiam eram até mesmo antagônicas a muitas das teses sustentadas pelas mais importantes e conhecidas confrarias Sufis e esta situação se agravava em relação às práticas. A literatura Sufi, por sua vez, evitava mencioná-los e isso talvez tenha contribuído para que muitos dentre historiadores do Islã e mesmo dos místicos posteriores tenham considerado as práticas dos Malâmati inferiores às dos Sufis. Aparentemente foram duas confrarias e vias místicas muito diferentes e concorrentes, pregando posturas e práticas contrárias, resultantes de um entendimento distinto acerca da evolução espiritual. Isso parece ter conduzido a conflitos e disputas entre as correntes. A postura mística dos Malamati era essencialmente sóbria e seu ensinamento rígido quanto à ostentação de manifestações da espiritualidade. Os Malâmati não permitiam que seus aspirantes tivessem

doutrinal ou obra biográfica e que da parte deles não se pode encontrar nada além de moral, virtudes e disciplina espiritual (riyâda). SULAMI. La Lucidez Implacable: Epístola de los hombres de la reprobación, p. 28. Sulami apresenta, nesta obra, uma compilação das crenças e atitudes fundamentais destes místicos pouco conhecidos a partir das informações obtidas, segundo suas palavras, pelos depoimentos de seu avô materno Ibn Nujayd - um Malâmati que foi discípulo de Abû 'Uthmân al-Hîrî, um dos principais sheikhs do círculo Malâmati do final do século nove. Também documenta passagens que teriam sido frutos da observação (ou mesmo participação direta, embora ele mesmo não assuma) nos círculos Malâmati de segunda geração, que ainda eram ativos durante seu tempo de vida.

${ }^{11}$ Cf. SVIRI, Hakîm al-Tirmidhî and the Malâmatî movement in early Sufism, p. 599 e TOUSSULIS, Sufism and the way of blame, p. 76.

${ }^{12}$ Na Epístola Malâmatiyya, lemos que "Hamdûn al-Qassâr diz a 'Abdullâh al-Hajjâm: É melhor para ti ser conhecido como 'Abdullâh al-Hajjâm (o assistente dos banhos) que como 'Abdullâh o Místico (al- 'Ârif), ou como 'Abdullâh o Asceta (al-Zâhid)". SULAMÎ, La Lucidez Implacable: Epístola de los hombres de la reprobación, p. 56. 
pretensões espirituais, proibiam-nos de falar de signos milagrosos ou carismas. Em virtude disso, tinham sérias críticas aos discípulos dos Sufis. Entendiam que estes eram deixados livremente às suas pretensões ilusórias durante o período de aprendizado. Acusavam os discípulos dos Sufis de manifestarem publicamente toda sorte de ilusões grosseiras ilusões a respeito do caminho místico e de se vangloriarem de suas realizações e carismas, "ridículas para todo espiritual sagaz", nas quais nada haveria de verdadeira espiritualidade. Deixados livremente às suas ilusões, os aspirantes, com o passar do tempo, acabariam acreditando nestas pretensões espirituais, entendendo a si mesmos como tendo atingido graus que sequer teriam tocado e, assim, iriam se afastando cada vez mais do caminho real e da verdade (haqq) de Deus.

Não somente se opunham à manifestação pública destes carismas (karâmât), mas provavelmente sequer acreditavam que fossem legítimas experiências interiores (ahwâl) ou que se configurassem em sinais da proximidade de Deus (walâya). Seriam somente ilusões e armadilhas. E, mesmo quando estes fossem legítimos, o que acreditavam ser um fenômeno bem mais raro do que os Sufis faziam crer, deveriam ser guardados para si mesmos, como um segredo da relação entre o místico e Deus. Os verdadeiros estados místicos, as estações espirituais, os dons especiais e os carismas são vistos pelos Malamati como pertencentes a Deus, portanto, as experiências reais dos místicos, deveriam ser entendidas não como propriedade dos místicos, mas como bens alheios confiados a eles, somente enquanto fiéis depositários que recebem aquilo para a realização de um determinado objetivo. Se o depositário trair a confiança do verdadeiro dono daqueles bens, não tornará a ser digno da confiança $^{13}$ de Deus, encerrando ali seu processo de desenvolvimento espiritual. Assim sendo, de ocultar estes carismas depende o cumprimento da missão para a qual aqueles dons foram "emprestados".

Como podemos notar, não é de surpreender que os Malamati tenham angariado muitos inimigos e detratores. Mas, por outro lado, estes místicos tiveram defensores de primeira linha, como o próprio Sulami e o, que é importante para nós, o mestre maior Ibn Arabi (Al-Sheikh Al-Akhbar) que, nos Futûhât al-Makkiyya ${ }^{14}$, situa-os no topo da hierarquia espiritual. O mesmo é repetido na Risalat al-anwar fima yunah sahib al-khalwa min al-asrar ("tratado sobre as luzes nos segredos concedidos àquele que empreende o recolhimento") 15 .

Entre os herdeiros há quem trate de chegar a Deus pela palavra de Moisés, Jesus, Shem, Isaac, Ismael, Abraão e outros; estes são os Sufis. São adeptos de diversos graus(...) Há também aqueles que seguem a palavra de Mohammad (paz e bênção sobre ele); estes são os Malamyya, os adeptos da permanência e as realidades ${ }^{16}$.

Sulami divide os mestres espirituais em três categorias: 1) Os sábios da Lei e das tradições e guias da Religião: estes, apesar de se consagrarem às ciências das regras gerais e

\footnotetext{
${ }^{13}$ Conforme Abû Zakariya al-Sinjî, transmitido por Abû Ahmad Ibn Isa: "Os estados místicos, para aqueles que são gratificados com eles, são como depósitos confiados a seu cuidado e se os mostram saem dos limites permitidos ao depositário". Muhammad ibn Al-Hasan, traça uma comparação com as relações sociais: "Não se tornará a ter confiança naquele a quem se confiou um segredo e o tenha revelado publicamente, e jamais tornarão a fazer-lhe confidências. Será mantido afastado, não tornará a gozar da sorte das relações familiares e da intimidade em relação a ele se transformará em frieza distante. Portanto, não se pode escolher ninguém que divulgue os segredos. O afeto em relação a ele ficará daí em diante excluído, completamente excluído". SULAMÎ, La Lucidez Implacable: Epístola de los hombres de la reprobación, p. 39.

${ }^{14}$ Cf. IBN ARABI, Futûhât, cap.73, questão II.

15 traduzido para os idiomas ocidentais modernos como Viagem ao Senhor do Poder, a partir da tradução inglesa intitulada Journey to the Lord of Power.

${ }^{16}$ IBN ARABI, Viaje al Señor del Poder, p. 55-6.
} 
dedicarem suas vidas a compilá-las, guardá-las, difundi-las e legá-las, não têm competência nos domínios da elite espiritual (al-khawass): as práticas místicas, as experiências interiores e a contemplação. 2) Acima deles estaria a elite da elite (khawass al-khawass). Interiormente contemplam o mundo oculto e exteriormente nada neles está em desacordo com a Lei. Estes são os homens do conhecimento de Deus. A estes Deus reservou o conhecimento e são distantes das preocupações e dos desejos dos homens comuns. São agraciados por favores excepcionais (ou carismas, karâmât). A parte oculta de seu ser olha para a realidade divina (al-haqq) e para os mistérios divinos, enquanto seus membros estão revestidos com a beleza dos atos de adoração que realizam. Nesta categoria estão os Sufis. 3) São aqueles aos quais Deus revestiu com a beleza interior de seus favores excepcionais, gratificou com sua proximidade (qurba), com ser admitido em Sua presença (zulfa) e ser unido a Ele (ittisâl). Nestes, toda separação foi superada e são confirmados nos graus sublimes da união, da proximidade e da relação íntima com Ele. Deus zela por eles e os oculta do mundo, não mostrando às criaturas nada mais do que seu aspecto exterior. Desse modo, apesar de serem os mais próximos de Deus, parecem ao vulgo distantes d'Ele, dedicados às ciências exotéricas, às disposições da Lei e dos bons costumes (adab). Por isso e por seu elevado estado espiritual, a realidade interior de seu ser não deixa rastro em seu exterior. Estes são os Malamati.

Talvez pareça estranho dedicarmos tanto tempo a um círculo místico oriental dos primeiros séculos do Islã, formado por personagens obscuros e não raramente anônimos. Mas, fizemos esta ampla digressão com o fim de demonstrar que a denominação Sufi está longe de ter sido originariamente a denominação geral aplicável aos místicos do Islã. Pelo contrário; fontes históricas e estudos atuais indicam que Sufi foi uma a denominação possivelmente auto imputada, de um círculo muito específico que floresceu durante os séculos IX e X na região de Bagdad. Desse modo, os termos sûfi, sûfiyya e tasawwuf designavam exclusivamente os mestres de Bagdad.

Uma das surpreendentes deduções do estudo das várias fontes Sufis e nãoSufis é que entre os séculos nono e décimo nem todos os místicos muçulmanos eram conhecidos como Sufis. Intitular os místicos muçulmanos com o nome abrangente Sufi e identificar a mística islâmica com tasawwuf parece ter sido resultado direto da literatura compilatória do século quatorze e mais tardia, com o Kitâb al-Ta'arruf de Kalâbâdhi, Kitâb al-Luma' de Sarrâj, Tabaqât al-sûfiyya de Sulamî e também, Al-Risâla fi 'ilm altasawwuf de Qushayrî e o Kashf al-mahjûb de Hujwîrî, pode-se traçar uma clara tentativa de apresentar um quadro amalgamado das diferentes escolas e centros, sem perder a perspectiva - embora sutil e tacitamente - da própria filiação e lealdade do compilador ${ }^{17}$.

Mais tardiamente, conforme já apontamos, a denominação foi estendida, e passamos a contar com Sufismos diferentes. Por vezes tão diferentes entre si que sequer concordam em muitos pontos. Isso ocorreu em virtude de vários processos ao longo da história: a disseminação do Islã em terras que dispunham de vertentes místicas próprias com características diferenciadas, como na Ásia e na África; pela assimilação de outras correntes místicas minoritárias, como os Qalandar; com a perseguição dos missionários Ismailis que se disfarçaram sob o já amplo manto do Sufismo; e pelo ocultamento por opção dos Malamati que parecem ter desaparecido completamente durante séculos. Mas, a questão se torna de fundamental importância ao questionarmos a escolha de Ibn Arabi como

${ }^{17}$ SVIRI, Hakîm al-Tirmidhî and the Malâmatî movement in early Sufism, p. 6o1. 
representante do Sufismo por Izutsu, diante do fato de que ele próprio considerava os mestres Malamati superiores.Citação longa (mais de 3 linhas) em fonte Spectral 11 pt, espaçamento simples $(1,0)$, recuo à esquerda de $4 \mathrm{~cm}$, alinhamento justificado, espaços anterior e posterior de $10 \mathrm{pt}$, com exemplo de referência à citação de uma obra de Schopenhauer abreviada de acordo com a lista de abreviaturas disponível na página da revista (W I, § 55, 350).

\section{Sufismo e Taoísmo: a origem xamânica}

Um ponto central no qual se apoia o estudo comparativo de Izutsu é a origem xamânica de ambos movimentos sapienciais - como iremos chamá-los a partir deste momento - para afastarmo-nos, ao menos por ora, dos termos "filosofia" e "religião", que serão retomados mais adiante. O Taoísmo é estudado por Izutsu como sendo uma elaboração metafísica de uma tradição originariamente xamânica que estava presente na região de Chu; provavelmente ele assim estabelece por ser o local onde os estudiosos localizam a redação do Dao De Jing. Em sua visão, a ideia sustentada por alguns scholars de que o livro seria uma compilação de ensinamentos de origens ou autores diversos seria errônea, já que seu teor reflete uma obra de cunho nitidamente pessoal. Para defender a relação com o xamanismo sublinha diversas passagens que teriam paralelos em textos anteriores, considerados produções de orientação xamânica.

Para Izutsu, ainda que não possamos identificar pistas claras na estrutura mesma da metafísica taoísta já plenamente formulada e estruturada em livro que indiquem seus antecedentes xamânicos "é inegável que na descrição filosófica do Dao que Lăozi fornece, por exemplo, há algo misterioso e primitivo que poderia indicar sua relação original com o xamanismo $^{18 "}$. Conforme o estudioso, os filósofos taoístas que produziram obras como Dao De Jing e Zhuāngzǐ eram, por uma parte, xamãs, no que se refere à base experimental de sua cosmovisão. Por outra parte, eram pensadores intelectuais que, não contentes com encontra-se no nível primitivo do xamanismo popular, exercitaram seu intelecto para elevar e elaborar sua visão original, convertendo-a em um sistema de conceitos metafísicos destinados a explicar a estrutura mesma do $\operatorname{ser}^{19}$. Já Wong retrocede mais nas raízes xamânicas do pensamento chinês e sugere que as raízes primevas do taoísmo estariam entre 3000 e 800 antes da Era Comum e remontariam a uma sociedade tribal assentada ao longo do Rio Amarelo (norte da China). O mais célebre chefe foi Yu, cuja lenda estabelece que não era um mortal comum, posto que não teve mãe e a ele são atribuídas uma série de maravilhas. "Todas as coisas que foram atribuídas a Yu por esta lenda caracterizam-no como um xamã ${ }^{20 "}$. A história do xamanismo chinês prosseguiria com a institucionalização das práticas divinatórias e oraculares a partir da dinastia Chou. Com o declínio do uso institucionalizado dessas práticas na dinastia Chou, o xamanismo teria sobrevivido ao Sul, na região do vale do Yang-Tsé, habitado pelos povos, considerados primitivos e bárbaros, de Ch'u, Wu e Yueh. Enquanto Chou abandonava as crenças nos espíritos e passava à elaboração de discursos mais propriamente racionalistas ${ }^{21}$, estes povos do Sul continuaram a crer nos poderes da natureza. Conforme a autora, esta seria a origem das práticas rituais do

\footnotetext{
${ }^{18}$ IZUTSU, Sufismo y Taoísmo, p. 28.

${ }^{19}$ Cf. IZUTSU, Sufismo y Taoísmo, p. 25.

${ }^{20}$ WONG, Taoism: An Essential Guide, p. 12.

${ }^{21}$ É no decurso de períodos conturbados, refletindo o longo processo de declínio que desintegra o edifício sócio-político dos Zhou, que são elaborados e aperfeiçoados discursos filosóficos”. CHENG, História do Pensamento Chinês, p. 60.
} 
taoísmo mágico ${ }^{22}$. Mas, mais adiante, reforça a origem xamânica também dos textos canônicos:

An even greater influence on Taoism came from shamanism's impact on the philosophy of Lao-Tzu and Chuang-Tzu. This influence is often unrecocnized, because many scholars consider the Taochia (philosophical Taoism) and the Tao-Chiao (religious Taoism) as opposing branches of Taoist thinking. A little known entry Ssuma Ch'ien's monumental work of history titled Shi-Chi (historical Records) in the biography of Lao-Tzu, reads, "Lao-Tzu was a native of C'hu, of the county of Fu of the village of Li". LaoTzu, the founder of the philosophy of Taoism lived in a society that had a strong shamanic culture. Moreover, several proeminent Chinese scholars have also recently $y^{23}$ noted similarities in language construction betwenn the Tao-Te-Ching and the literature of the C'hu culture. Similarly with ChuangTzu... ${ }^{24}$

Este não parece ser um entendimento geral, posto que alguns autores concebem a diferença fundamental entre Daojia e Daojiao. Para estes, o xamanismo somente seria uma influência principal no Daojiao (taoísmo religioso ou mágico), mas não teria tido importância na formulação dos cânones do Daojia (taoísmo filosófico). Para efeitos de nosso estudo, esta separação não é necessária, sequer importante, posto que, em qualquer tradição, temos uma formulação metafísica, ética e nitidamente filosófica entre os intelectuais e, ao lado desta, uma religião popular que segue seu curso de acordo com as adaptações, sincretismos e crenças gerais da população. Certo é que não podemos fazer a distinção tal como é feita em religiões institucionalizadas, nas quais a religiosidade popular se contrapõe justamente a uma expressão "oficial" ou cânone institucional. No caso do Taoísmo, como este inexiste, ela se contrapõe à formulação metafísica. Assim, seria mais adequado falar da religião, tal como falamos da cultura, tendo assim uma religiosidade popular em contraposição a uma religiosidade erudita ${ }^{25}$. Este termo seria menos restrito às religiões institucionalizadas e consequentemente aplicável a casos diversos ao redor do mundo.

Por xamanismo, Izutsu pretende designar um tipo particular de sabedoria que surge da experiência existencial própria de "pessoas dotadas da capacidade de ver coisas em um nível suprassensível de consciência através de um encontro extático com o Absoluto e de imagens arquetípicas às quais dá lugar". Note-se aqui o peso da questão da imagem, que está presente no nível do contato com o suprassensível "ver coisas em um nível suprassensível", bem como na transformação em imagens para que a experiência possa ser comunicada “imagens arquetípicas às quais dá lugar”. A definição apresentada por Izutsu poderia ser facilmente reconhecida por qualquer místico especulativo ou gnóstico, independente da religião de origem, sendo, portanto, plenamente aplicável aos conteúdos presentes na obra de Ibn 'Arabi.

A questão da imagem é um ponto muito importante de intersecção, se considerarmos que uma das bases do pensamento de Ibn Arabi é justamente o chamado

\footnotetext{
${ }^{22}$ WONG, op. cit., p. 16.

${ }^{23}$ Note-se que “recentemente” é relativo à primeira edição da obra de Wong, em 1951.

${ }^{24}$ WONG, op. cit., p. 18.

${ }^{25}$ Ainda que não seja necessariamente uma erudição no sentido das letras, mas daquele que obtém um conhecimento tradicional do sagrado bem elaborado, normalmente instruído por figuras cujo saber religioso ou espiritual é de notório reconhecimento na sociedade.
} 
"mundo imaginal". Para Ibn Arabi, este é um mundo intermediário entre a chamada realidade sensível e as realidades divinas ou superiores ${ }^{26}$, o locus no homem no qual essas realidades tomam forma e podem ser experienciadas e comunicadas. "Como o maior teórico muçulmano da imaginação, ele foi capaz de utilizar - com perfeita consciência do que estava fazendo - as possibilidades da expressão poética obtidas através da percepção imaginal ${ }^{27}$. A partir da caracterização do aspecto xamânico a partir do imaginal - ou do sonho - como aponta no Taoísmo, o termo passou a parecer menos estranho ao ser aplicado a Ibn Arabi e outros expoentes da mística em geral.

Eliade nos informa que o xamanismo, strictu sensu é um fenômeno oriental, mais especificamente localizado na Ásia central e setentrional. "Como se sabe, os povos árticos, siberianos e centro-asiáticos são formados em sua maior parte por caçadores-pescadores ou por pastores-criadores de gado. São caracterizados por certo nomadismo ${ }^{28 ”}$. Esse mesmo nomadismo pode ser notado nas tribos originárias da península arábica e de boa parte do oriente médio, berço do Islã, e Eliade mesmo não considera os fenômenos xamânicos como restritos a esta área geográfica: "O xamanismo turco-mongol, na forma em que se apresenta, está inclusive bastante impregnado de influências orientais e, ainda que existam outros xamanismos livres de influxos tão caracterizados e tão recentes, esses também não são originários $^{29}$ ". Ainda que não seja fato comprovado que a origem deste todo chamado sufismo tenha ocorrido nessa região geográfica ${ }^{30}$, ou seja, na península arábica, já que essa visão dependeria justamente da concepção acerca da origem do Sufismo e de sua vinculação necessária ao Islã ou não, bem como das variantes da mística já apresentadas, o elemento apontado por Eliade pode sugerir a possibilidade de preexistência de um xamanismo primitivo nas tribos árabes pré-islâmicas.

Somos obrigados a retornar aqui, de certo modo, ao ponto anterior, já que nos deparamos com a discussão sobre a origem histórica do Sufismo e desses movimentos místicos islâmicos em geral. Há aqui também interpretações diferentes, que divergem tanto em relação à origem de cada um em particular quanto sobre sua própria relação com o Islã. Há quem diga que o Sufismo é uma expressão mística própria do Islã e não pode ser entendido fora deste contexto religioso. Mas, há quem diga que provém de um conhecimento muito mais antigo que o advento do Islã e teria sido adequado e reformulado para sobreviver sob a nova religião oficial. Lembremos que a tradição Malamati concorre com o sufismo original, estabelecida em um local geográfico bem mais ao leste, em Khorasan, região na qual o xamanismo é bem documentado.

Resta-nos discutir aqui, portanto, a partir do que já foi exposto sobre a construção histórica do Sufismo, de que modo o estudo de Izutsu deve ser entendido e de que modo ele contribui realmente para os estudos sobre o tema. E a primeira questão que levantamos é:

\footnotetext{
26 "Revelation begins with dream visions rather than sense perception because intelligible are closer to the imagination than they are to sense perception. Sense perception is the lower side while meaning is the higher and subtle side. Imagination stands between the two". IBN ARABI apud. CHITTICK, Imaginal Worlds: Ibn al'Arabi and the Problem of Religious Diversity, p. 75.

${ }^{27}$ CHITTICK, Imaginal Worlds: Ibn al-'Arabi and the Problem of Religious Diversity, p. 67.

${ }^{28}$ ELIADE, O Xamanismo e as Técnicas Arcaicas do Êxtase, p. 25.

${ }^{29}$ ELIADE, op. cit., p. 28.

30 Há estudos que apontam a origem persa do Sufismo. A perspectiva muda consideravelmente se concordarmos que o Sufismo é uma expressão essencialmente islâmica ou se optarmos pela ideia de que é um conhecimento anterior que se adaptou ao Islã. E muda também consideravelmente se entendermos o Sufismo como o conjunto da mística islâmica, ou se o caracterizarmos historicamente como uma confraria originada em Bagdá, que mantinha sensíveis diferenças com grupos místicos concorrentes e a palavra foi posteriormente adaptada pelos historiadores para significar um conjunto mais amplo de expressões místicas.
} 
seria o estudo de Izutsu uma obra de "religiões comparadas", ou teria ele intenção de alcançar outro objetivo que não fosse tão dependente do conceito de religião?

Conforme Thoha, embora ninguém possa questionar que os textos escolhidos por Izutsu representam fielmente a tradição que denominamos Taoísmo ${ }^{31}$, o mesmo não aconteceria em relação a Ibn 'Arabi.

O caso é totalmente diferente em relação a Ibn 'Arabi no Sufismo, muito menos no Islã. Embora seus seguidores e admiradores reconheçam-no como al-Shaykh al-Akbar, (o maior dos mestres) seus pensamentos não são, de modo algum a corrente dominante no Sufismo. Ao contrário disso, ainda, eles são considerados pela maioria dos 'ulamā', (estudiosos islâmicos) como desviantes do esquema convencional do Sufismo e, sobretudo, do pensamento islâmico em geral. A principal acusação contra Ibn 'Arabī é seu pensamento incomum e não ortodoxo, que é frequentemente identificado como panteísmo, a unidade da existência (waḥdat al-wujūd). Uma vez que esta linha de pensamento sufista jamais foi conhecida na tradição dos primórdios do Islã, em especial, na tradição do Profeta, os estudiosos muçulmanos tendem a considerá-la como uma heresia ou heterodoxia $\left(\text { bid ' }^{\prime} \text { h }\right)^{32}$.

O que Thoha parece não ter percebido é que, em nenhum momento, Izutsu tentou realizar exatamente um trabalho de "religiões comparadas", comparando o taoísmo enquanto religião com o Islã. Assim sendo, a acusação de heresia que o pensamento de Ibn 'Arabi sofre pelos teólogos islâmicos mais ortodoxos não vem ao caso. É fato que a obra de Ibn Arabi é polêmica e foi estudada e interpretada a partir de perspectivas diversas. Takeshita aponta a possibilidade de que a opção de Izutsu por Ibn Arabi tenha sido "inspirada pela famosa obra de Corbin L'imagination creatrice dans le soufisme d'Ibn Arabi (1958), embora ele não mencione Corbin em seu livro. No entanto, as abordagens dos dois estudiosos são muito diferentes 33". Ele reforça que o conceito de unidade da existência (waḥdat al-wujūd) que é central no pensamento de Ibn Arabi, e cuja interpretação peculiar é uma das razões de acusação de heresia ${ }^{34}$, não é muito destacado por Corbin, ao contrário do que faz Izutsu.

Um outro ponto que queremos levantar aqui é que, talvez Thoha tenha toda razão ao apontar que Ibn 'Arabi não representa a expressão comum e tradicional do Sufismo - tal como o entendemos nos dias atuais. E talvez a razão disso resida exatamente na apologia que ele faz da proposta Malamati. Esta é a razão pela qual nos dedicamos tanto a questionar o significado mesmo de Sufismo, em sua construção histórica e também nos detivemos tanto às poucas informações disponíveis sobre a corrente Malamati neste artigo.

O malāmī, conforme Ibn 'Arabi o descreve, sabe a cada momento que Deus age sem causas secundárias, e não através delas, e que elas são então o véu do Uno sem Par. Mas Ele escolheu este véu e não cabe ao servo rompê-lo. Então o malāmī, como o homem comum - e ele é um homem comum no seu mais completo sentido, através de sua consciente e voluntária conformidade

\footnotetext{
${ }^{31}$ "As far as Taoism is concerned, I think nobody will dispute or disagree with Izutsu". THOHA, Izutsu's approach to the comparative study of religions: an assessment of his Sufism and Taoism, p. 185.

${ }^{2}$ THOHA, op. cit., p. 186

33 TAKESHITA, Toshihiko Izutsu's contribution to Islamic Studies, p. 80

34 Sobre o tema ver a discussão do uso e interpretação do termo por BAKRI, Oneness of Being (waḥdat alwujūd).
} 
com a ordem divina das coisas - submete-se à cadeia das causas secundárias ${ }^{35}$.

$\mathrm{Na}$ via inversa da crítica a uma suposta tentativa de um trabalho de religiões comparadas, numa perspectiva bem mais filosófica, Rizvi aponta que o trabalho de Izutsu tem uma contribuição extremamente relevante ao estudo da filosofia comparada e da filosofia da mística ${ }^{36}$. É esta a perspectiva que defendemos aqui. Não se trata aqui de um estudo comparativo entre religiões, pois, conforme apontamos desde o início, a aplicação mesma do termo religião, tanto ao Taoísmo quanto à mística islâmica é em si já controversa. Mas, se entendermos como duas propostas filosóficas - ainda que não totalmente conformes à matriz grega a qual o ocidente está acostumado a encarcerar o termo filosofia - teremos uma perspectiva diferente. E mais, se entendermos a questão, tal como faz Rizvi, estando assentada em certas questões fundamentais, a saber, "o que entendemos por mística e o que é exatamente o conceito de 'consciência pura'37”, e voltarmos nossa atenção para a comunicação da experiência mística ${ }^{38}$, talvez compreendemos melhor a que se destina um trabalho como este 39 .

A partir do que foi discutido até o momento, a questão principal desponta em nosso horizonte: de que maneira uma manifestação de origem xamânica pode dar lugar a um discurso sistemático tão elaborado que só pode ser entendido no âmbito da filosofia?

\section{A título de conclusão: do xamanismo à filosofia}

Partimos aqui do entendimento de que Izutsu jamais tencionou realizar um trabalho de "religiões comparadas". Isso parece claro por diferentes razões, dentre elas, porque não explica o taoísmo enquanto religião e porque em nenhum momento compara o Taoísmo com o Islã enquanto religião. Izutsu realizou um estudo comparativo de ideias fundamentais presentes no Taoísmo clássico e na obra de Ibn 'Arabi. Assim sendo, poderíamos nos aproximar mais da realidade se entendêssemos como um trabalho de filosofias comparadas do que de religiões. Além disso, como já foi apontado no início, há dificuldades em situar ambas linhas de pensamento no interior do âmbito da religião tal como comumente concebida.

Apesar de não fornecer exatamente uma definição do xamanismo, Eliade descreve o processo que faz com que alguém se torne um xamã, ou os elementos que o indivíduo deve ter para ser considerado como tal: "O reconhecimento do xamã não ocorre até que ele tenha recebido tanto a instrução de ordem extática (sonhos, transes, etc), quanto a transmissão da ordem tradicional (técnicas xamânicas, nomes e funções dos espíritos, mitologia, genealogia do clã, linguagem secreta, etc) ${ }^{40}$ ". Portanto, ainda que seja consequência do que Rizvi chama de "consciência pura", ou seja, uma prática caracterizada por uma iniciação por chamamento ou eleição, a transmissão tradicional dos conhecimentos religiosos cumpre uma função importante e definida. A cadeia de transmissão de conhecimentos é igualmente

35 CHODKIEWICZ, Seal of the Saints: Profethood and Sainthood in the doctrine of Ibn 'Arabi, p. 110

${ }^{36}$ RIZVI, Communicating Pure Consciousness Events: Using lzutsu to Address a Problem in the Philosophy of Mysticism, p. 158.

37 RIZVI, op. cit., p. 158.

${ }^{8}$ RIZVI, op. cit, p. 161.

39 "Izutsu's work on the whole may be described as an attempt to make philosophical sense of the pure consciousness experience and immediate knowledge of ultimate reality. He has written about precisely those philosophical traditions in which intuitive, experiential and non-propositional knowledge play a significant part in articulating metaphysics and the psychology of the self". RIZVI, op. cit., p. 166.

$4^{\circ}$ ELIADE, O Xamanismo e as Técnicas Arcaicas do Êxtase, p. 29. 
importante, havendo uma instrução por parte dos mais velhos ou reconhecidos, estabelecendo uma linhagem espiritual seja ela familiar - no sentido hereditário - ou não.

Esta necessidade de reconhecimento por parte da comunidade faz com que aquele que obteve a experiência - que aqui podemos chamar de mística, tenha que comunicar de algum modo aquilo que viveu ou experienciou. E esta comunicação deve se dar no âmbito de uma linguagem compartilhada pelos demais "xamãs", ou pelos "religiosos" de seu tempo. Ele deve primeiro ser compreendido para depois ser reconhecido, a fim de integrar um determinado círculo já estabelecido de "espiritualidade".

Mas, por outro lado, se devem, através da linguagem pela qual comunicam suas experiências, se aproximar da religião estabelecida, utilizando símbolos e imagens comuns em seu meio, por outro lado, são indivíduos que, de certo modo, necessariamente se afastam da religião organizada ou oficial. Eliade esclarece

... contentemo-nos em dizer que os xamãs são seres que se singularizam, no seio das respectivas sociedades por determinados traços que, nas sociedades da Europa moderna, representam os signos de uma "vocação" ou, ao menos, de uma "crise religiosa". A intensidade de sua própria experiência religiosa os separa do resto da comunidade. Isso equivale a dizer que seria mais razoável citar o xamanismo entre as místicas do que entre aquilo que habitualmente se chama uma "religião"41.

Entendendo então o xamanismo como mística, podemos comparar a outras concepções que, embora utilizem outros termos, referem-se a este mesmo processo. Assim, poderíamos dizer que ambos os pensamentos aqui abordados se enquadram naquilo que Bergson denomina "religião dinâmica", em oposição ao arcabouço de crenças e rituais que compõem o que chamamos normalmente de religião - a religião estática. Conforme Bergson, a religião estática desempenha um papel fundamental na manutenção da sociedade fechada gerando, dentro de seus próprios limites, as tradições, os rituais e as regras morais, e reforçando a identidade entre os membros, trabalhando junto à necessidade, pela sobrevivência, expressa inclusive pela vontade de defender o grupo contra as eventuais investidas de outros grupos. Já para a religião dinâmica, os rituais e práticas advindos do hábito não possuem a menor importância, significado, ou mesmo, função ${ }^{42}$. A religião dinâmica sustenta o homem pelo próprio movimento que o recoloca no fluxo do impulso criador. A religião dinâmica, de acordo com Bergson, significa, por outro lado, um contato direto com o esforço criador que a vida manifesta. Nesse sentido, o conceito de religião dinâmica coincide com o de Mística e com o que foi apresentado aqui como xamanismo. $\mathrm{O}$ místico completo, ou o grande místico, é o indivíduo que ultrapassa os limites da resistência da materialidade imposta à espécie e da individualidade imposta à sua existência particular, continuando e prolongando assim a ação divina. Assim sendo, a relação entre as duas formas de religião é íntima, mas são processos de natureza diferente: "Concebemos, pois, a religião como a cristalização operada por um resfriamento sábio, do que o misticismo veio depositar, queimando na alma da humanidade43".

E, para Bergson, a mística seria infinitamente superior à religião estática, aqui denominada simplesmente religião: "a religião está para o misticismo como a vulgarização está para a ciência44”. Tendo estabelecido a relação entre o caráter xamânico atribuído por

\footnotetext{
${ }^{41}$ Id. Ibid., p.25.

${ }^{42}$ Mesmo "a prece é indiferente à sua expressão verbal, é uma elevação da alma que poderia dispensar a fala". BERGSON, As Duas Fontes da Moral e da Religião, p. 166.

43 BERGSON, op. cit., p. 196.

44 BERGSON, op. cit., p. 197.
} 
Izutsu ao Taoísmo e ao Sufismo de Ibn Arabi com a religião, falta-nos indicar como algo que se origina como um xamanismo pode dar origem a uma proposta filosófica tão sofisticada. Como o contato com o material tradicionalmente depositado na religiosidade precedente enquanto religião estática - das sociedades em questão as intuições destas personalidades excepcionais são formuladas a partir do que já se encontra depositado no arcabouço cultural das respectivas comunidades, com o fim de serem comunicadas. Mas, por outro lado, necessariamente mantêm sua natureza distinta, sua particularidade muitas vezes indescritível, já que decorrem, como diria Bergson, do contato com o impulso vital ou criador. Essa é a razão pela qual esses pensamentos de certos indivíduos excepcionais, apesar de aparentemente estarem inseridos em alguma linha religiosa ou cultural anterior a eles, mantêm sempre um caráter de novidade e originalidade assim como algum aspecto de mistério, posto que a experiência que conduziu à obra é em si indescritível. Assemelham-se mais a filosofias do que propriamente a formulações religiosas correntes, ainda que a própria filosofia jamais consiga dar conta deles completamente. São expressões refinadas eruditas e elaboradas em virtude da própria qualidade da experiência de consciência daquele que a viveu.

\section{Referências}

BAKRI, Aladdin, "Oneness of Being (wahdat al-wujūd)", Journal of the Muhyiddin Ibn 'Arabi Society, Volume 51, 2012, disponível em http://www.ibnarabisociety.org/articles/oneness-ofbeing.html.

BERGSON, Henri. As Duas Fontes da Moral e da Religião. Rio de Janeiro: Zahar, 1978.

CHENG, Anne. História do Pensamento Chinês. Petrópolis: Vozes, 2008.

CHITTICK, William C. Imaginal Worlds: Ibn al-'Arabi and the Problem of Religious Diversity. New York: SUNY Press, 1994.

CHODKIEWICZ, Michel. Seal of the Saints: Prophethood and Sainthood in the doctrine of Ibn 'Arabi. Cambridge: The Islamic Texts Society,1993.

DAFTARY, Farhad. Ismailis in Medieval Muslim Societies. London/New York: I.B. Tauris; The Institute of Ismaili Studies, 2005.

ELIADE, Mircea. O Xamanismo e as Técnicas Arcaicas do Êxtase. São Paulo: Martins Fontes, 1998.

IBN AL 'ARABI, The Meccan revelations (Futûhât al Makkiya) 2 vols. New York: Pir Press, 2004 .

IBN ARABI, Viaje al Señor del Poder (Risalat al-anwar...). Málaga: Editorial Sirio, 1988.

IZUTSU, Toshihiko. Sufismo y Taoísmo. (2 vols). Madrid: Siruela, 2004.

NURBAKHSH, Javad. Simbolismo Sufi - Vol. 3. Madrid: Editorial Nur, 2005.

RIZVI, Sajjad H. "Communicating Pure Consciousness Events: Using lzutsu to Address a Problem in the Philosophy of Mysticism”. In, THOHA, A. M. (org.) Japanese Contribution to Islamic Studies: The Legacy of Toshihiko Izutsu Interpreted. Kuala Lumpur: IIUM Press and Japan Foundation, 2010. pp. 157-170

SCHIPPER, Kristofer; VERELLEN, Franciscus (eds), The Taoist Canon: A Historical Companion to the Daozang, Chicago: Chicago University Press, 2004. 
SULAMI. La Lucidez Implacable: Epístola de los hombres de la reprobacion (Risalat alMalâmatiyya). Barcelona: Ediciones Obelisco, 2003.

SVIRI, Sara. "Hakîm al-Tirmidhî and the Malâmatî movement in early Sufism." In L. Lewisohn (ed.), Classical Persian Sufism. London: KNP. 1993, 583-613.

TEISER, Stephen F., VERELLEN Franciscus. "Buddhism, Daoism, and Chinese Religion”. In: Cahiers d'Extrême-Asie, vol. 20, 2011. pp. 1-12;

TEROL ROJO, Gabriel. Lectura de la relación religiosa y filosófica del daoísmo chino. Actas del XI Congreso Andaluz de Filosofía: Filosofía y religión, retos y desafíos actuales, Granada: AAFI, 2016. p. 230-241.

TAKESHITA, Masataka. “Toshihiko Izutsu's contribution to Islamic Studies”. Journal of International Philosophy. 2016, p. 78-81.

THOHA, Anis Malik. "Izutsu's approach to the comparative study of religions: an assessment of his Sufism and Taoism”. Japanese Contribution to Islamic Studies: The Legacy of Toshihiko Izutsu Interpreted. Kuala Lumpur: IIUM Press and Japan Foundation, 2010. pp. 181-190.

TOUSSULIS, Yannis. Sufism and the way of blame. Wheaton: Quest Books, 2010.

WONG, Eva. Taoism: An Essential Guide. Boston: Shambhala Publications, 1997. (1a edição 1951). 